\title{
Bart syndrome
}

\author{
*Sathika Amarasekara ${ }^{1}$, Shyama Basnayake ${ }^{2}$ \\ Sri Lanka Journal of Child Health, 2021; 50(1): 173-175 \\ DOI: http://dx.doi.org/10.4038/sljch.v50i1.9425 \\ (Key words: Bart syndrome, epidermolysis bullosa, aplasia cutis)
}

\section{Background}

Bart syndrome (BS) or aplasia cutis congenita (ACC) type VI, is characterized by congenital localized absence of skin, nail abnormalities and muco-cutaneous blistering lesions ${ }^{1}$. We present a newborn with the classic triad of BS.

\section{Case report}

One-day old neonate was transferred from a local hospital to a tertiary care centre for further management of a cutaneous defect involving both lower limbs. He was the first born infant of healthy unrelated parents without similar skin disorders in the family. Baby was born at 38 gestational weeks by emergency caesarean section done due to meconium stained liquor. His birth weight was $2900 \mathrm{~g}$. Apgar score was 9 at one minute and 10 at five minutes. The antenatal period was uneventful.

On clinical examination, there were sharply demarcated, glistening red ulcerations involving both lower extremities. The lesions involved the plantar and dorsal aspects of the right foot, sparing only the last three toes, and extending over the anteromedial aspect of the leg up to the thigh (Figures 1 and 2). The left leg was involved to a lesser extent than the right leg. Blistering lesions were noted in right hand and face (Figure 3). Toe nails were absent in right first, second, and third toes (figure 4). Mucous membrane lesions were noted in the mouth (Figure 5).

Further blistering lesions tended to occur with minor friction. Rest of the systemic examination was unremarkable and the results of haematological and biochemical investigations were within normal limits. Bart syndrome was diagnosed based on the

\begin{tabular}{l}
\hline${ }^{1}$ Senior Registrar in Neonatology, ${ }^{2}$ Consultant \\
Neonatologist, Lady Ridgeway Hospital for \\
Children, Colombo, Sri Lanka \\
${ }^{*}$ Correspondence: sathika3.ama@gmail.com
\end{tabular}

https://orcid.org/0000-0002-0018-4597 (Keceived on 28 September 2919: Accepted after revision on 22 November 2019)

The authors declare that there are no conflicts of interest

Personal funding was used for the project.

Open Access Article published under the Creative

Commons Attribution CC-BY (c) (i) License triad of epidermolysis bullosa, congenital absence of skin in lower extremities and absent toe nails. Baby was managed conservatively with local fusidic acid while maintaining hydration. Parents were counselled on precautions and good prognosis of the condition.

\section{Discussion}

Bruce J Bart in 1966 first described a large kindred with aplasia cutis congenita (ACC) involving lower extremities, blistering lesions of skin and/or oral mucosa, absence or dystrophy of nails and improvement of the blistering process after puberty ${ }^{1-3}$. However, he could not classify the disease due to the unavailability of ultrastructural and immune histochemical studies at that time ${ }^{4}$. Subsequent reports suggested this syndrome to be a subtype of a major form of epidermolysis bullosa ${ }^{4}$. However, Zelickson et al later performed ultrastructural and immunological analysis of the skin biopsy of the descendants of the original family and determined that BS is a subtype of dystrophic epidermolysis bullosa ${ }^{4}$. Our patient had all three clinical features described by Bart in his original family.

The inheritance is autosomal dominant with complete penetrance but sporadic cases have been reported $^{1-6}$. Zelickson et al has performed genetic linkage analysis of the descendants of the original family, mapping the gene to chromosome $3 p$ at or close to the site of the gene encoding type VII collagen $^{4}$. Our patient belongs to the sporadic category as there was no family history. Even though various hypotheses have been proposed, exact pathophysiology of ACC is not known. Proposed mechanisms include intrauterine vascular compromise, trauma, infections and medications ${ }^{7}$.

BS lesions are commonly unilateral, appearing in lower extremities as sharply demarcated, glistening red ulceration extending upwards from the dorsal aspect of the foot over the $\operatorname{shin}^{1}$. Blisters primarily involve hands, legs, feet and rarely mucous membranes ${ }^{4}$. The lesions tend to occur increasingly in warm weather and with excessive friction ${ }^{4}$. Nails could be completely absent or dystrophic to varying degrees ${ }^{4}$. Renal abnormalities, pyloric stenosis, ureteral stenosis, flattened nose, broad nasal root, wide-set eyes and rudimentary ear development have also been described ${ }^{1,5}$. None of these abnormalities were detected in our patient. 


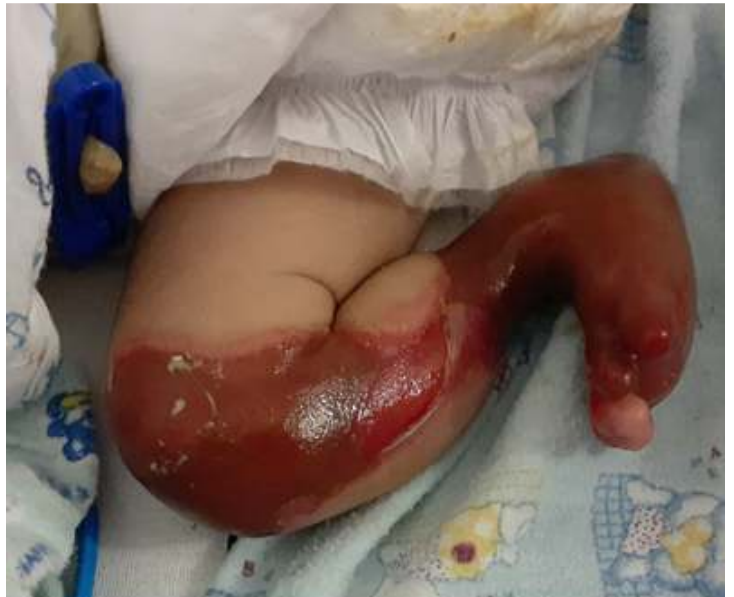

Figure 1: Absent skin involving right leg

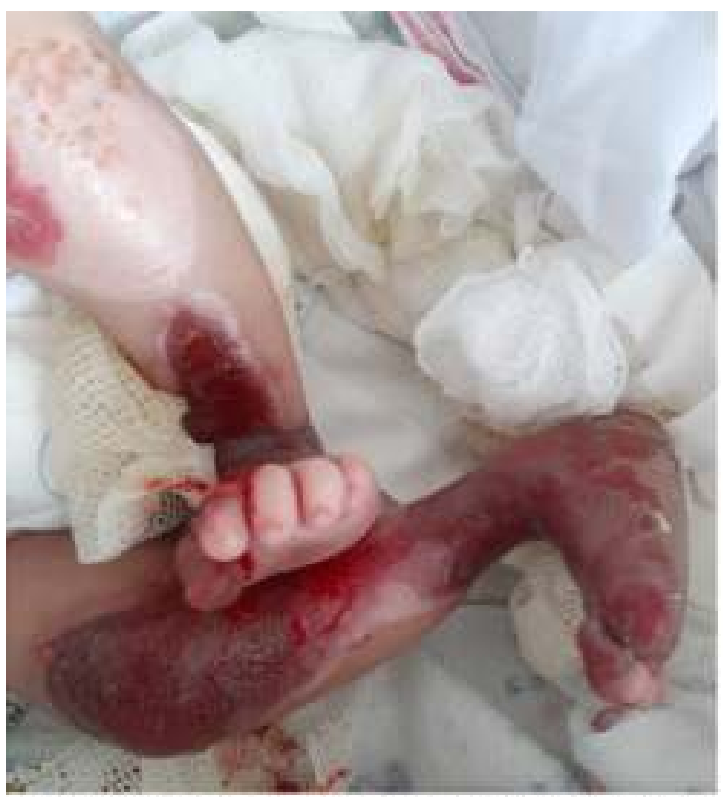

Figure 2: Aplasia cutis involving lower limbs

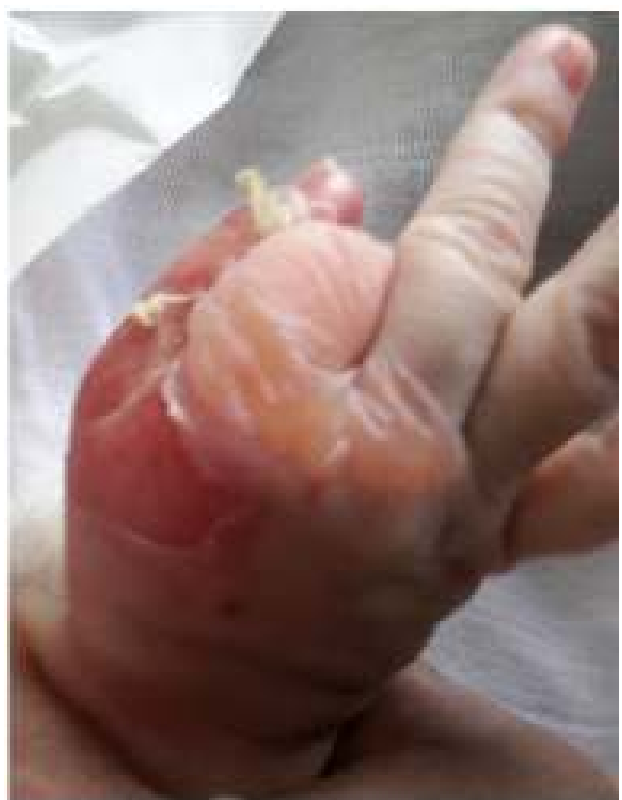

Figure 3: Blistering lesions of right hand

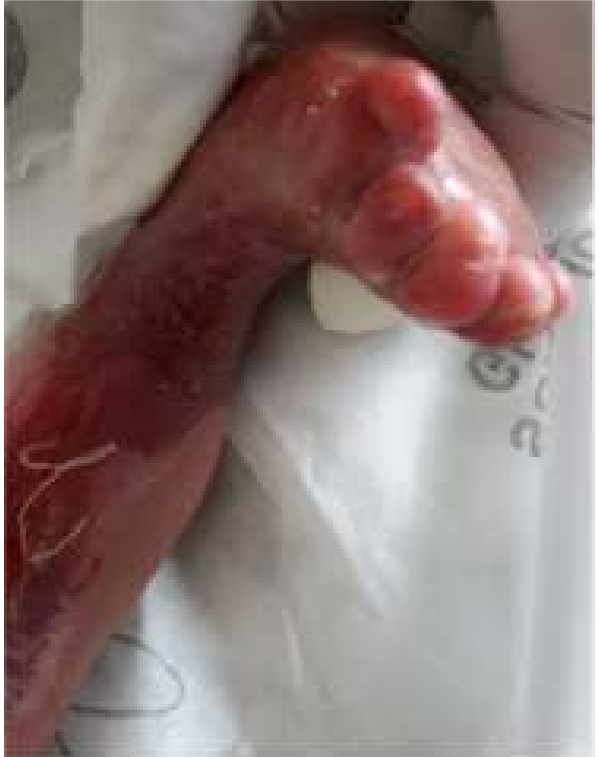

Figure 4: Absent toe nails

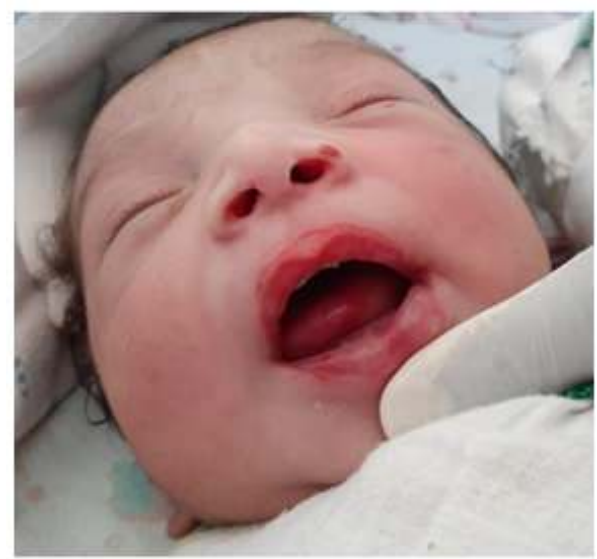

Figure 5: Mucosal lesions

*Permission given by parents to publish photograph

The diagnosis of BS is based on unique clinical signs but histological evaluation of skin may aid in confirming the diagnosis ${ }^{3,8}$. Blister formation is below the lamina densa with poorly formed anchoring fibrils which are reduced in number ${ }^{4}$. Uninvolved skin has normal morphological appearance ${ }^{4}$ Management is commonly conservative while preventing infections and allowing affected lesions to heal ${ }^{8}$. Prophylactic antibiotics are usually not recommended and patient should be closely followed up for serious complications such as haemorrhage, hypothermia and hypoglycaemia ${ }^{1,8}$. The prognosis of the disease is generally good with normal life expectancy ${ }^{1-6,8}$.

The areas of absent skin usually heal without scar formation and blistering lesions tend to reduce in severity and frequency with age ${ }^{4}$. 


\section{References}

1. Alfayez Y, Alsharif S, Santli A. A case of aplasia cutis congenita type VI: Bart syndrome. Case Reports in Dermatology 2017; 9:112-8.

https://doi.org/10.1159/000478889

PMid: 29033814 PMCid: PMC5624250

2. Bajaj DR, Qureshi A. Bart's syndrome: a case report. Journal of Pakistan Association of Dermatologists 2008; 18: 106-8.

3. Rajpal A, Mishra R, Hajirnis K, Shah M, Nagpur N. Bart's syndrome. Indian Journal of Dermatology 2008; 53(2): 8890.

https://doi.org/10.4103/0019-5154.41655

PMid: 19881996 PMCid: PMC2763726

4. Zelickson B, Matsumura K, Kist D, Epstein EH, Bart BJ. Bart's Syndrome: Ultrastructure and genetic linkage. Archives of Dermatology 1995; 131(6): 663-8.

https://doi.org/10.1001/archderm.131.6.66 3

PMid: 7778916
5. Bart BJ, Lussky RC. Bart syndrome with associated anomalies. American Journal of Perinatology. 2005; 22(7):365-9.

https://doi.org/10.1055/s-2005-871657 PMid: 16215923

6. Iqbal AM, Shenoy MM, Pinto M, Amin VB, Hegde SP. Absent skin at birth with blistering: Bart's Syndrome? Archives of Medicine and Health Sciences 2017; 5:133-5.

7. Aplasia cutis congenita. Available from: https://emedicine.medscape.com/article/11 10134-overview

8. Kulalı F, Bas AY, Kale Y, Celik IH, Demirel N, Apaydın S. Type VI aplasia cutis congenita: Bart's syndrome. Case Reports in Dermatological Medicine 2015; 2015: 549825.

https://doi.org/10.1155/2015/549825

PMid: 26609453 PMCid: PMC4644546 